\title{
THREE PASSAGES IN SS. IGNATIUS AND POLYCARP.
}

THE following passages seem to contain unnoticed echoes of the thought or expression of New Testament writings.

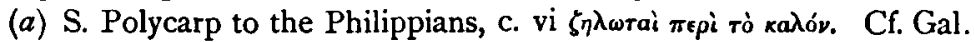

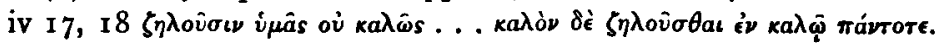

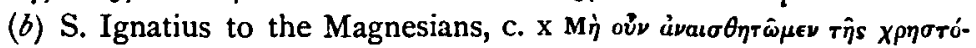

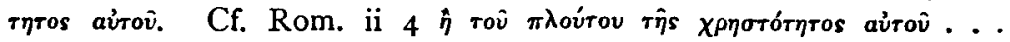
karappoveis. For what follows in S. Ignatius cf. Rom. ii 5-9.

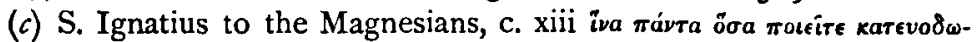

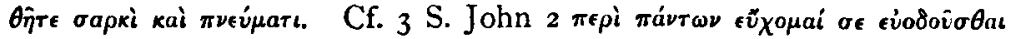

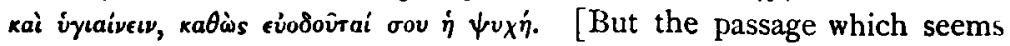

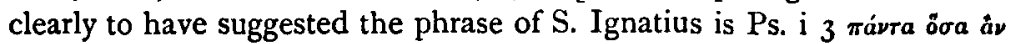

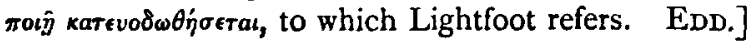

T. NICKLIN. 